\title{
Prevalence of Multiple Chronic Conditions Among Medicare Beneficiaries, United States, 2010
}

\author{
Kimberly A. Lochner, ScD; Christine S. Cox, MA \\ Suggested citation for this article: Lochner KA, Cox CS. Prevalence of Multiple Chronic Conditions Among Medicare \\ Beneficiaries, United States, 2010. Prev Chronic Dis 2013;10:120137. DOI: http://dx.doi.org/10.5888/pcd10.120137 [
}

PEER REVIEWED

\section{Abstract}

\section{Introduction}

The increase in chronic health conditions among Medicare beneficiaries has implications for the Medicare system. The objective of this study was to use the US Department of Health and Human Services Strategic Framework on multiple chronic conditions as a basis to examine the prevalence of multiple chronic conditions among Medicare beneficiaries.

\begin{abstract}
Analysis
We analyzed Centers for Medicare and Medicaid Services administrative claims data for Medicare beneficiaries enrolled in the fee-for-service program in 2010. We included approximately 31 million Medicare beneficiaries and examined 15 chronic conditions. A beneficiary was considered to have a chronic condition if a Medicare claim indicated that the beneficiary received a service or treatment for the condition. We defined the prevalence of multiple chronic conditions as having 2 or more chronic conditions.
\end{abstract}

\section{Results}

Overall, $68.4 \%$ of Medicare beneficiaries had 2 or more chronic conditions and $36.4 \%$ had 4 or more chronic conditions. The prevalence of multiple chronic conditions increased with age and was more prevalent among women than men across all age groups. Non-Hispanic black and Hispanic women had the highest prevalence of 4 or more chronic conditions, whereas Asian or Pacific Islander men and women, in general, had the lowest.

\section{Summary}

The prevalence of multiple chronic conditions among the Medicare fee-for-service population varies across demographic groups. Multiple chronic conditions appear to be more prevalent among women, particularly nonHispanic black and Hispanic women, and among beneficiaries eligible for both Medicare and Medicaid benefits. Our findings can help public health researchers target prevention and management strategies to improve care and reduce costs for people with multiple chronic conditions.

\section{Introduction}

The increase in chronic health conditions among Medicare beneficiaries has far-reaching implications for the Medicare system $(1,2)$. Among Medicare beneficiaries, not only are hypertension, high cholesterol, heart disease, and diabetes highly prevalent, but most beneficiaries have multiple chronic conditions. Medicare beneficiaries with multiple chronic conditions are the heaviest users of health care services, including such high-cost services as hospitalizations and emergency department visits, which translates into increased Medicare spending. For example, the two-thirds of beneficiaries with 2 more chronic conditions accounted for $93 \%$ of Medicare spending, and the one-third with 4 or more chronic conditions accounted for almost three-fourths of Medicare spending (3).

Although research has focused on chronic conditions such as hypertension, diabetes, and heart conditions (1), the US Department of Health and Human Services (HHS) Initiative on multiple chronic conditions calls for the need to enhance the understanding of chronic condition comorbidities. The HHS Initiative's strategic framework on multiple chronic conditions offers an organizing structure to address multiple chronic conditions through research, 
interventions, and health care management and indicates the need to increase the evidence base on the epidemiology of multiple chronic conditions $(4,5)$.

The objective of this study was to use the HHS Strategic Framework on multiple chronic conditions as a basis to examine the prevalence of multiple chronic conditions among Medicare beneficiaries. In combination with the other articles in this issue of Preventing Chronic Disease that address multiple chronic conditions, this study begins to fill the gaps and improve our understanding of the prevalence of multiple chronic conditions across different populations using different data sources.

\section{Analysis}

Medicare is the US federal health insurance program for people aged 65 or older, people younger than 65 with certain disabilities, and people of any age with end-stage renal disease. We examined Centers for Medicare and Medicaid Services (CMS) administrative enrollment and claims data for Medicare beneficiaries enrolled in the fee-for-service program for 2010. These CMS data are available from the CMS Chronic Condition Data Warehouse (CCW), a research database with $100 \%$ of Medicare enrollment and fee-for-service claims data that is designed to make CMS data more readily available to support research. (6).

In 2010, there were more than 50 million Medicare beneficiaries. The study population included only those Medicare beneficiaries continuously enrolled in Medicare fee-for-service parts A and B, also known as original or traditional Medicare, for 2010. To obtain a study population of beneficiaries continuously enrolled in fee-for-service Medicare for the entire year, we excluded beneficiaries with any Medicare Advantage enrollment during the year, approximately 17 million beneficiaries, and beneficiaries who first became eligible for Medicare after January of the calendar year. We included beneficiaries who died during the year up to their date of death if they met other inclusion criteria. Our 2010 Medicare fee-for-service study population comprised approximately 31 million beneficiaries and represented approximately $66 \%$ of the total Medicare population in 2010.

We included the following 15 chronic conditions in our examination of multiple chronic conditions: Alzheimer's disease and related dementia, arthritis, asthma, atrial fibrillation, cancer (breast, colorectal, lung, prostate), chronic kidney disease, chronic obstructive pulmonary disease, depression, diabetes, heart failure, hyperlipidemia, hypertension, ischemic heart disease, osteoporosis, and stroke. We considered Medicare beneficiaries to have a chronic condition if the CMS administrative data had a claim indicating that beneficiaries received a service or treatment for the condition. For example, to identify a beneficiary with hyperlipidemia during 2010, at least 1 inpatient, skilled nursing facility, or home health claim or 2 outpatient or carrier claims had to include any of the following diagnosis codes from the International Classification of Diseases, 9th Revision, Clinical Modification: 272.0, 272.1, 272.2, 272.3, 272.4. Detailed information on the identification of chronic conditions in the CCW is available elsewhere (6). Chronic conditions were counted and grouped into 3 categories (o or 1, 2 or 3, and 4 or more); multiple chronic conditions were defined as having 2 or more chronic conditions. We also identified the most common dyads of chronic conditions among beneficiaries with at least 2 chronic conditions, as well as the most common triads among beneficiaries with at least 3 chronic conditions.

We examined the treated prevalence of multiple chronic conditions by select Medicare beneficiary characteristics: sex, age in years $(<65,65-74,75-84$, and $\geq 85)$, dual Medicaid enrollment, also known as "dual eligible," and race/ethnicity (non-Hispanic white, non-Hispanic black, Hispanic, Asian or Pacific Islander, American Indian or Alaska Native, and non-Hispanic other race.). Because of known limitations in Medicare enrollment data for the classification of a beneficiary's race/ethnicity, we used the race/ethnicity variable available in the CCW that is based on a validated algorithm that improves the accuracy of race/ethnicity classification (7).

\section{Results}

Among our population of fee-for-service Medicare beneficiaries, $17.1 \%$ percent were younger than 65, who receive Medicare primarily as a result of having a disability, and $82.9 \%$ were aged 65 or older (Table 1 ). Female beneficiaries were older than male beneficiaries, particularly in the group aged 85 or older $(17.8 \%$ of women compared with $10.7 \%$ of men). Our study population was 81.2\% non-Hispanic white, 9.6\% non-Hispanic black, 5.7\% Hispanic, and 2.2\% Asian or Pacific Islander. Race/ethnicity did not vary greatly between men and women. Approximately one-fifth (21.6\%) of Medicare beneficiaries were also eligible for Medicaid; more female beneficiaries were dual-eligible than men.

Overall, $68.4 \%$ of Medicare beneficiaries had 2 or more chronic conditions and $36.4 \%$ had 4 or more chronic conditions (Table 2). The prevalence of multiple chronic conditions $(\geq 2)$ increased with age and was higher for women than men across all age groups. Among beneficiaries younger than $65,48.7 \%$ of men had multiple chronic conditions compared with $58.8 \%$ of women. In this age group for both men and women, the prevalence of multiple chronic conditions was highest for non-Hispanic blacks and Hispanics (approximately 50\% for men and 60\%-64\% for women) and lowest for Asian/Pacific Islanders (46.8\% for men and 50.3\% for women). Among beneficiaries 65 and older, 
$69.1 \%$ of men had multiple chronic conditions compared with $73.4 \%$ of women. Among men 65 or older, the highest prevalence of multiple chronic conditions was among non-Hispanic whites (69.6\%) and the lowest among Hispanics (63.1\%), but among women in this age group, the highest prevalence was among non-Hispanic blacks (79.6\%) and the lowest among Asian/Pacific Islanders and non-Hispanic whites. When we compared the prevalence of 4 or more chronic conditions with the prevalence of 2 or more, the patterns were similar for beneficiaries younger than 65 but varied for beneficiaries 65 or older (Table 2).

The prevalence of multiple chronic conditions, in particular 4 or more chronic conditions, increased with age ( Table 3). Non-Hispanic black men had the highest prevalence of 4 or more chronic conditions among men aged 65 to 74 and 75 to 84 (34.2\% and 46.9\%, respectively). For men 85 or older, non-Hispanic whites, non-Hispanic blacks and Hispanics had similar rates of 4 or more chronic conditions (54.6\%). For women across all older age groups, nonHispanic black and Hispanic women had the highest prevalence of 4 or more chronic conditions.

In general, dual-eligible beneficiaries had a higher prevalence of multiple chronic conditions than nondual beneficiaries, and female dual-eligible beneficiaries had a higher prevalence than male dual-eligible beneficiaries at every age (Table 4). Among female dual-eligible beneficiaries, the prevalence of multiple chronic conditions was $81.2 \%$ for those aged 65 to $74,88.0 \%$ for those aged 75 to 84 , and $91.7 \%$ for those aged 85 or older. The prevalence of 4 or more chronic conditions was high for this vulnerable population; approximately two-thirds of beneficiaries that were dual-eligible and aged 85 or older (both men and women) had 4 or more chronic conditions.

Among beneficiaries with 2 or more chronic conditions, the most prevalent dyads included hypertension, hyperlipidemia, diabetes, and ischemic heart disease (Table 5). The most common dyad across all sex and age groups was hypertension and hyperlipidemia; however, among beneficiaries younger than 65 , the diabetes and hyperlipidemia was also highly prevalent. Women differed from men in that depression and arthritis were present in the most common dyads. We examined triads of chronic conditions only for beneficiaries who had at least 3 chronic conditions. For beneficiaries younger than 65 , the most common triad of chronic conditions was diabetes, hypertension, and hyperlipidemia; $35.4 \%$ of men and $32.0 \%$ of women had these 3 conditions (Table 6). Among beneficiaries 65 years or older, ischemic heart disease, hypertension, and hyperlipidemia was a common triad; $42.6 \%$ of men and $29.4 \%$ of women had these 3 conditions.

\section{Summary}

The magnitude of CMS data allowed us to examine multiple chronic conditions by relevant sociodemographic characteristics to identify the Medicare beneficiaries who may benefit most from targeted interventions and health care management strategies aimed at delivering health care in a more effective and efficient manner. More than 21 million Medicare fee-for-service beneficiaries had 2 or more chronic conditions in 2010, and more than 11 million had 4 or more. Our findings support the goals and objectives of the HHS Strategic Framework on multiple chronic conditions, specifically the fourth goal that addresses the need for research to fill knowledge gaps about the epidemiology of multiple chronic conditions (4). Our findings also demonstrate the variation in multiple chronic conditions across demographic groups. Because the number of multiple chronic conditions increases with age and because women generally live longer than men do, the prevalence of multiple chronic conditions is expected to be higher for women. We found that female beneficiaries had a higher prevalence of multiple chronic conditions than male beneficiaries across all age groups. We also found that the prevalence of multiple chronic conditions varied by race/ethnicity. NonHispanic black and Hispanic women often had the highest prevalence of multiple chronic conditions. Multiple chronic conditions were more prevalent among the vulnerable population of dual-eligible beneficiaries, who tend to have low incomes or disabilities and be aged 85 or older.

Other studies may have included a larger number and broader set of chronic conditions to estimate the prevalence of multiple chronic conditions $(1,2,8)$. Our estimates were determined on the basis of guidelines established by the HHS Strategic Framework, which defines multiple chronic conditions as having 2 or more chronic conditions and identifies a proposed set of 20 common chronic conditions (9). Our study included 15 of the 20 proposed HHS conditions but excluded several behavioral and other illnesses that are included in the HHS Framework (ie, autism spectrum disorder, schizophrenia, substance abuse [drug and alcohol disorders], HIV, and hepatitis, as well as conditions considered chronic by other sources) (10).

Our study has limitations. We identified chronic conditions through administrative claims in which discrepancies in physician coding could have introduced errors or lack of treatment for a condition could have resulted in misclassification., Also, our findings are applicable to the Medicare fee-for-service population. The CCW does not contain managed care claims or encounter data; therefore, examining multiple chronic conditions among Medicare beneficiaries enrolled in Medicare Advantage plans was not possible. However, our study did include more than 31 million Medicare beneficiaries, including disabled beneficiaries and those dually eligible for Medicaid. 
Multiple chronic conditions lead to poor health outcomes, the use of high-cost health services, and increased Medicare spending. Our findings should provide health policy makers and the public health research community a better understanding of the burden of chronic conditions among the Medicare fee-for-service population and provide preliminary insights into developing prevention and management strategies that will improve care and reduce costs for people with chronic conditions.

\section{Acknowledgments}

The authors gratefully acknowledge Anand Parekh, Rick Goodman, Sam Posner, and members of the HHS Multiple Chronic Conditions Data Initiative Work Group for the discussions and collaborations leading to the development of this article. This research received no specific grant from any funding agency in the public, commercial, or nonprofit sectors.

\section{Author Information}

Corresponding Author: Kimberly A. Lochner, ScD, Centers for Medicare and Medicaid Services, Office of the Regional Administrator, 61 Forsyth St SW, Ste 4T20, Atlanta, GA 30303-8909. Telephone: 404-562-7140. E-mail:

Kimberly.Lochner@cms.hhs.gov.

Author Affiliation: Christine S. Cox, Centers for Medicare and Medicaid Services, Baltimore, Maryland.

\section{References}

1. Anderson GF. Medicare and chronic conditions. N Engl J Med 2005;353(3):305-9. CrossRef 芯 PubMed 图

2. Thorpe KE, Ogden LL, Galactionova K. Chronic conditions account for rise in Medicare spending from 1987 to 2006. Health Aff (Millwood) 2010;29(4):718-24. CrossRef 虑 PubMed 图

3. Centers for Medicare and Medicaid Services. Chronic conditions among Medicare beneficiaries, chart book. Office of Information Products and Data Analytics; 2011. https://www.cms.gov/Research-Statistics-Data-andSystems/Statistics-Trends-and-Reports/TheChartSeries/ChronicConditionsChartBook.html. Accessed May 29, 2012.

4. US Department of Health and Human Services. HHS Initiative on Multiple Chronic Conditions. Office of the Assistant Secretary for Health; 2012. http://www.hhs.gov/ash/initiatives/mcc/. Accessed May 29, 2012.

5. Parekh AK, Goodman RA, Gordon C, Koh HK. HHS Interagency Workgroup on Multiple Chronic Conditions. Managing multiple chronic conditions: a strategic framework for improving health outcomes and quality of life. Public Health Rep 2011;126(4):460-71. PubMed 图

6. Centers for Medicare and Medicaid Services. Chronic condition data warehouse. http://www.ccwdata.org/index.htm. Accessed May 29, 2012.

7. Eicheldinger C, Bonito A. More accurate racial and ethnic codes for Medicare administrative data. Health Care Finance Rev 2008;29(3):27-42. PubMed 圈

8. Agency for Healthcare Research and Quality. Healthcare cost and utilization project. chronic condition indicator (CCI) for ICD-9-CM. http://www.hcup-us.ahrq.gov/toolssoftware/chronic/chronic.jsp. Accessed July 16, 2012.

9. Goodman RA, Posner S, Huang ES, Koh HK. Defining and measuring chronic conditions: 21st century imperatives for research, policy, program, and practice. Prev Chronic Dis . Forthcoming. PubMed 鹿

10. Schneider KA, O'Donnell BE, Dean D. Prevalence of multiple chronic conditions in the United States' Medicare population. Health Quality Life Outcome 2009;7(82).

\section{Tables}

Table 1. Study Population Characteristics for Medicare Fee-for-Service Beneficiaries, 2010

\begin{tabular}{|c|c|c|c|}
\hline Characteristic & $\begin{array}{c}\text { Total, } \%(\mathrm{~N}= \\
\mathbf{3 1}, \mathbf{3 1 3}, \mathbf{3 3 1})\end{array}$ & $\begin{array}{c}\text { Men, } \%(n= \\
13,845,487)\end{array}$ & $\begin{array}{c}\text { Women, \% }(n= \\
17,467,844)\end{array}$ \\
\hline \multicolumn{4}{|l|}{ Age, y } \\
\hline$<65$ & 17.1 & 20.4 & 14.6 \\
\hline
\end{tabular}




\begin{tabular}{|c|c|c|c|}
\hline Characteristic & $\begin{array}{c}\text { Total, } \%(\mathrm{~N}= \\
\mathbf{3 1}, \mathbf{3 1 3}, \mathbf{3 3 1})\end{array}$ & $\begin{array}{l}\text { Men, } \%(n= \\
13,845,487)\end{array}$ & $\begin{array}{c}\text { Women, \% (n = } \\
17,467,844)\end{array}$ \\
\hline$\geq 65$ & 82.9 & 79.7 & 85.4 \\
\hline $65-74$ & 39.3 & 41.3 & 37.6 \\
\hline $75-84$ & 29.0 & 27.7 & 30.0 \\
\hline$\geq 85$ & 14.6 & 10.7 & 17.8 \\
\hline \multicolumn{4}{|l|}{ Sex } \\
\hline Male & 44.2 & NA & $\mathrm{N} A$ \\
\hline Female & 55.8 & NA & $\mathrm{N} A$ \\
\hline \multicolumn{4}{|l|}{ Race/ethnicity } \\
\hline Non-Hispanic white & 81.2 & 81.0 & 81.3 \\
\hline Non-Hispanic black & 9.6 & 9.4 & 9.8 \\
\hline Hispanic & 5.7 & 6.0 & 5.5 \\
\hline Non-Hispanic Asian/Pacific Islander & 2.2 & 2.1 & 2.2 \\
\hline $\begin{array}{l}\text { Non-Hispanic American } \\
\text { Indian/Alaska Native }\end{array}$ & 0.5 & 0.5 & 0.5 \\
\hline Non-Hispanic other race & 0.9 & 1.0 & $0 . \varepsilon$ \\
\hline \multicolumn{4}{|l|}{ Dual-eligibility ${ }^{a}$} \\
\hline Yes & 21.6 & 19.1 & 23.7 \\
\hline No & 78.4 & 80.9 & 76.3 \\
\hline
\end{tabular}

Abbreviation: NA, not applicable.

a Refers to Medicare beneficiaries who also were eligible for Medicaid.

Table 2. Percentage of Medicare Fee-for-Service Beneficiaries With Chronic Conditions, by Sex, Age, and Race/Ethnicity, 2010

\begin{tabular}{|c|c|c|c|}
\hline \multirow[b]{2}{*}{ Characteristic } & \multicolumn{3}{|c|}{ No. of Chronic Conditions } \\
\hline & 0 or 1 & 2 or 3 & $\geq 4$ \\
\hline Total $(\mathrm{N}=\mathbf{3 1}, \mathbf{3 1 3}, \mathbf{3 3 1})$ & 31.5 & 32.0 & 36.4 \\
\hline \multicolumn{4}{|c|}{ Men } \\
\hline Aged $<65(n=2,817,692)$ & 51.3 & 26.0 & 22.7 \\
\hline Non-Hispanic white & 51.9 & 26.3 & 21.9 \\
\hline Non-Hispanic black & 50.1 & 25.2 & 24.8 \\
\hline Hispanic & 49.4 & 25.6 & 25.0 \\
\hline Non-Hispanic Asian/Pacific Islander & 53.2 & 25.4 & 21.4 \\
\hline Non-Hispanic American Indian/Alaska Native & 52.2 & 25.7 & 22.1 \\
\hline Non-Hispanic other race & 51.0 & 26.3 & 22.7 \\
\hline Aged $\geq 65(n=11,027,795)$ & 30.9 & 31.2 & 37.9 \\
\hline Non-Hispanic white & 30.4 & 31.7 & 37.9 \\
\hline Non-Hispanic black & 31.5 & 28.3 & 40.2 \\
\hline Hispanic & 36.9 & 26.0 & 37.1 \\
\hline Non-Hispanic Asian/Pacific Islander & 32.1 & 33.0 & 34.9 \\
\hline
\end{tabular}




\begin{tabular}{|c|c|c|c|}
\hline \multirow[b]{2}{*}{ Characteristic } & \multicolumn{3}{|c|}{ No. of Chronic Conditions } \\
\hline & 0 or 1 & 2 or 3 & $\geq 4$ \\
\hline Non-Hispanic American Indian/Alaska Native & 33.1 & 29.8 & 37.1 \\
\hline Non-Hispanic other race & 37.8 & 30.9 & 31.3 \\
\hline \multicolumn{4}{|c|}{ Women } \\
\hline Aged $<65(n=2,548,598)$ & 41.2 & 30.3 & 28.5 \\
\hline Non-Hispanic white & 42.7 & 30.5 & 26.5 \\
\hline Non-Hispanic black & 36.0 & 30.2 & 33.8 \\
\hline Hispanic & 39.8 & 29.1 & 31.0 \\
\hline Non-Hispanic Asian/Pacific Islander & 49.6 & 28.7 & 21.6 \\
\hline Non-Hispanic American Indian/Alaska Native & 41.5 & 30.2 & 28.3 \\
\hline Non-Hispanic other race & 46.8 & 29.4 & 23.8 \\
\hline Aged $\geq 65(n=14,919,246)$ & 26.6 & 34.1 & 39.3 \\
\hline Non-Hispanic white & 27.2 & 34.5 & 38.3 \\
\hline Non-Hispanic black & 20.5 & 32.9 & 46.7 \\
\hline Hispanic & 24.8 & 28.9 & 46.4 \\
\hline Non-Hispanic Asian/Pacific Islander & 27.8 & 35.3 & 36.5 \\
\hline Non-Hispanic American Indian/Alaska Native & 27.6 & 33.0 & 39.4 \\
\hline Non-Hispanic other race & 34.3 & 33.1 & 32.6 \\
\hline
\end{tabular}

Table 3. Percentage of Medicare Fee-for-Service Beneficiaries Aged $\geq 65$ With Chronic Conditions, by Sex, Expanded Age, and Race/Ethnicity, 2010

\begin{tabular}{|c|c|c|c|}
\hline \multirow[b]{2}{*}{ Characteristic } & \multicolumn{3}{|c|}{ No. of Chronic Conditions } \\
\hline & 0 or 1 & 2 or 3 & $\geq 4$ \\
\hline Total $(n=25,947,041)$ & 28.4 & 32.9 & 38.7 \\
\hline \multicolumn{4}{|c|}{ Men } \\
\hline Aged $65-74(n=5,719,126)$ & 38.4 & 32.5 & 29.0 \\
\hline Non-Hispanic white & 38.2 & 33.2 & 28.6 \\
\hline Non-Hispanic black & 36.3 & 29.5 & 34.2 \\
\hline Hispanic & 43.4 & 27.0 & 29.6 \\
\hline Non-Hispanic Asian/Pacific Islander & 40.2 & 34.0 & 25.8 \\
\hline Non-Hispanic American Indian/Alaska Native & 37.7 & 30.3 & 32.0 \\
\hline Non-Hispanic other race & 42.0 & 31.7 & 26.3 \\
\hline Aged 75-84 $(n=3,830,486)$ & 24.4 & 30.8 & 44.8 \\
\hline Non-Hispanic white & 24.0 & 31.3 & 44.7 \\
\hline Non-Hispanic black & 25.6 & 27.4 & 46.5 \\
\hline Hispanic & 29.9 & 25.4 & 44.7 \\
\hline Non-Hispanic Asian/Pacific Islander & 24.7 & 33.4 & 42.0 \\
\hline Non-Hispanic American Indian/Alaska Native & 27.3 & 29.5 & 43.2 \\
\hline Non-Hispanic other race & 28.0 & 30.2 & $41 . \varepsilon$ \\
\hline
\end{tabular}




\begin{tabular}{|c|c|c|c|}
\hline \multirow[b]{2}{*}{ Characteristic } & \multicolumn{3}{|c|}{ No. of Chronic Conditions } \\
\hline & 0 or 1 & 2 or 3 & $\geq 4$ \\
\hline Aged $\geq 85(n=1,478,183)$ & 18.6 & 27.0 & 54.5 \\
\hline Non-Hispanic white & 18.1 & 27.4 & 54.6 \\
\hline Non-Hispanic black & 21.4 & 24.0 & 54.6 \\
\hline Hispanic & 23.5 & 21.9 & 54.6 \\
\hline Non-Hispanic Asian/Pacific Islander & 20.4 & 28.3 & 51.3 \\
\hline Non-Hispanic American Indian/Alaska Native & 23.8 & 27.5 & 48.7 \\
\hline Non-Hispanic other race & 27.1 & 23.5 & 49.4 \\
\hline \multicolumn{4}{|c|}{ Women } \\
\hline Aged $65-74(n=6,571,342)$ & 35.5 & 35.8 & 28.7 \\
\hline Non-Hispanic white & 36.8 & 36.1 & 27.1 \\
\hline Non-Hispanic black & 25.8 & 35.4 & 38.8 \\
\hline Hispanic & 31.4 & 31.4 & 37.3 \\
\hline Non-Hispanic Asian/Pacific Islander & 35.7 & 37.2 & 27.1 \\
\hline Non-Hispanic American Indian/Alaska Native & 33.0 & 33.8 & 33.2 \\
\hline Non-Hispanic other race & 40.5 & 34.7 & 24.8 \\
\hline Aged $75-84(n=5,247,284)$ & 21.5 & 34.5 & 44.0 \\
\hline Non-Hispanic white & 22.1 & 35.1 & 42.8 \\
\hline Non-Hispanic black & 16.2 & 32.0 & 51.7 \\
\hline Hispanic & 19.0 & 27.5 & 53.5 \\
\hline Non-Hispanic Asian/Pacific Islander & 21.5 & 34.8 & 43.7 \\
\hline Non-Hispanic American Indian/Alaska Native & 22.9 & 32.7 & 44.4 \\
\hline Non-Hispanic other race & 26.5 & 33.4 & 40.2 \\
\hline Aged $\geq 85(n=3,100,620)$ & 16.3 & 30.0 & 53.7 \\
\hline Non-Hispanic white & 16.4 & 30.5 & 53.1 \\
\hline Non-Hispanic black & 13.7 & 27.6 & 58.7 \\
\hline Hispanic & 15.7 & 23.5 & 60.8 \\
\hline Non-Hispanic Asian/Pacific Islander & 18.7 & 30.7 & 50.6 \\
\hline Non-Hispanic American Indian/Alaska Native & 18.9 & 30.5 & 50.7 \\
\hline Non-Hispanic other race & 26.5 & 25.9 & 47.6 \\
\hline
\end{tabular}

Table 4. Percentage of Medicare Fee-for-Service Beneficiaries With Chronic Conditions by Sex, Age, and Dual-Eligibility Status $\left.{ }^{(N}=31,313,331\right), 2010$

\begin{tabular}{|l|r|r|r|}
\hline \multirow{2}{*}{ Characteristic } & \multicolumn{3}{|c|}{ No. of Chronic Conditions } \\
\cline { 2 - 5 } & \multicolumn{5}{|c|}{$\mathbf{0}$ or $\mathbf{2}$ or 3 } & \multicolumn{2}{|c|}{$\geq \mathbf{4}$} \\
\hline Aged $<\mathbf{6 5}$ & \multicolumn{2}{|c|}{ Men } \\
\hline Dual & 51.3 & 26.0 & 22.7 \\
\hline Nondual & 49.2 & 27.1 & 23.7 \\
\hline
\end{tabular}




\begin{tabular}{|c|c|c|c|}
\hline \multirow[b]{2}{*}{ Characteristic } & \multicolumn{3}{|c|}{ No. of Chronic Conditions } \\
\hline & 0 or 1 & 2 or 3 & $\geq 4$ \\
\hline \multicolumn{4}{|c|}{ Men } \\
\hline Aged $65-74$ & 38.4 & 32.5 & 29.0 \\
\hline Dual & 26.9 & 27.3 & 45.8 \\
\hline Nondual & 39.8 & 33.1 & 27.1 \\
\hline Aged 75-84 & 24.4 & 30.8 & 44.8 \\
\hline Dual & 18.2 & 24.0 & 57.8 \\
\hline Nondual & 25.2 & 31.6 & 43.2 \\
\hline Aged $\geq 85$ & 18.6 & 27.0 & 54.5 \\
\hline Dual & 11.5 & 21.1 & 67.4 \\
\hline Nondual & 19.6 & 27.8 & 52.6 \\
\hline \multicolumn{4}{|c|}{ Women } \\
\hline Aged $<65$ & 41.2 & 30.3 & 28.5 \\
\hline Dual & 38.3 & 30.4 & 31.3 \\
\hline Nondual & 45.4 & 30.0 & 24.5 \\
\hline Aged $65-74$ & 35.5 & 35.8 & 28.7 \\
\hline Dual & 18.7 & 30.0 & 51.2 \\
\hline Nondual & 38.4 & 36.8 & 24.8 \\
\hline Aged 75-84 & 21.5 & 34.5 & 44.0 \\
\hline Dual & 12.0 & 25.9 & 62.1 \\
\hline Nondual & 23.6 & 36.3 & 40.2 \\
\hline Aged $\geq 85$ & 16.3 & 30.0 & 53.7 \\
\hline Dual & 8.3 & 24.1 & 67.6 \\
\hline Nondual & 18.9 & 32.0 & 49.2 \\
\hline
\end{tabular}

a Dual eligibility refers to beneficiaries that are eligible to receive benefits under both the Medicare and Medicaid programs.

Table 5. Five Most Prevalent Chronic Condition Dyads Among Medicare Fee -for-Service Beneficiaries, by Sex and Age Group ( $N=21,437,857), 2010^{a}$

\begin{tabular}{|l|r|}
\hline Dyad by Sex and Age Group & \multicolumn{1}{|c|}{ Prevalence, \% } \\
\hline$<\mathbf{6 5}$ & 45.2 \\
\hline Hypertension and hyperlipidemia & 37.9 \\
\hline Diabetes and hyperlipidemia & 31.0 \\
\hline Ischemic heart disease and hyperlipidemia & 29.6 \\
\hline Diabetes and hypertension & 24.6 \\
\hline Ischemic heart disease and hypertension & \\
\hline$\geq \mathbf{6 5}$ & 56.0 \\
\hline Hypertension and hyperlipidemia & \\
\hline
\end{tabular}




\begin{tabular}{|l|r|}
\hline Dyad by Sex and Age Group & \multicolumn{1}{|c|}{ Prevalence, \% } \\
\hline Ischemic heart disease and Hyperlipidemia & 44.6 \\
\hline Ischemic heart disease and hypertension & 39.0 \\
\hline Diabetes and hyperlipidemia & 33.9 \\
\hline Diabetes and hypertension & 28.6 \\
\hline \multicolumn{1}{|c|}{ Women } & \\
\hline$<\mathbf{6 5}$ & 39.9 \\
\hline Hypertension and hyperlipidemia & 35.0 \\
\hline Diabetes and hyperlipidemia & 29.7 \\
\hline Depression and hyperlipidemia & 29.4 \\
\hline Arthritis and hyperlipidemia & 27.5 \\
\hline Diabetes and hypertension & 53.5 \\
\hline$\geq \mathbf{6 5}$ & 36.8 \\
\hline Hypertension and hyperlipidemia & 32.9 \\
\hline Arthritis and hyperlipidemia & 30.0 \\
\hline Ischemic heart disease and hyperlipidemia & 26.7 \\
\hline Diabetes and hyperlipidemia & \\
\hline Arthritis and hypertension & \\
\hline
\end{tabular}

a Medicare beneficiaries had to have at least 2 of the chronic conditions listed.

Table 6. Five Most Prevalent Chronic Condition Triads Among Medicare Fee -for-Service Beneficiaries, by Sex and Age Group ( $N=16,481,558), 2^{2010^{a}}$

\begin{tabular}{|c|c|}
\hline Triad by Sex and Age Group & Prevalence, \% \\
\hline \multicolumn{2}{|c|}{ Men } \\
\hline \multicolumn{2}{|l|}{$<65$} \\
\hline Diabetes, hypertension, and hyperlipidemia & 35.4 \\
\hline Ischemic heart disease, hypertension, and hyperlipidemia & 30.1 \\
\hline Diabetes, ischemic heart disease, and hyperlipidemia & 25.3 \\
\hline Diabetes, ischemic heart disease, and hypertension & 20.1 \\
\hline Diabetes, chronic kidney disease, and hyperlipidemia & 18.8 \\
\hline \multicolumn{2}{|l|}{$\geq 65$} \\
\hline Ischemic heart disease, hypertension, and hyperlipidemia & 42.6 \\
\hline Diabetes, hypertension, and hyperlipidemia & 32.1 \\
\hline Diabetes, ischemic heart disease, and hyperlipidemia & 25.9 \\
\hline Diabetes, ischemic heart disease, and hypertension & 22.3 \\
\hline Arthritis, hypertension, and hyperlipidemia & 21.8 \\
\hline \multicolumn{2}{|c|}{ Women } \\
\hline \multicolumn{2}{|l|}{$<65$} \\
\hline Diabetes, hypertension, and hyperlipidemia & 32.0 \\
\hline
\end{tabular}


Preventing Chronic Disease I Prevalence of Multiple Chronic Conditions Among Medi... Page 10 of 10

\begin{tabular}{|l|r|}
\hline Triad by Sex and Age Group & Prevalence, \% \\
\hline Arthritis, hypertension, and hyperlipidemia & 23.5 \\
\hline Depression, hypertension, and hyperlipidemia & 23.1 \\
\hline Ischemic heart disease, hypertension, and hyperlipidemia & 21.9 \\
\hline Diabetes, arthritis, and hyperlipidemia & 19.9 \\
\hline$\geq 6 \mathbf{5}$ & 29.6 \\
\hline Arthritis, hypertension, and hyperlipidemia & 29.4 \\
\hline Ischemic heart disease, hypertension, and hyperlipidemia & 27.6 \\
\hline Diabetes, hypertension, and hyperlipidemia & 20.8 \\
\hline Ischemic heart disease, arthritis, and hyperlipidemia & 18.3 \\
\hline Diabetes, ischemic heart disease, and hyperlipidemia & \\
\hline
\end{tabular}

a Medicare beneficiaries had to have at least 3 of the chronic conditions listed.

The opinions expressed by authors contributing to this journal do not necessarily reflect the opinions of the U.S. Department of Health and Human Services, the Public Health Service, the Centers for Disease Control and Prevention, or the authors' affiliated institutions.

The RIS file format is a text file containing bibliographic citations. These files are best suited for import into bibliographic management applications such as EndNote $\mathbf{s}^{\mathrm{s}}$, Reference Manager download is available at each application's web site.

For Questions About This Article Contact pcdeditor@cdc.gov

Page last reviewed: April 25, 2013

Page last updated: April 25, 2013

Content source: National Center for Chronic Disease Prevention and Health Promotion

Centers for Disease Control and Prevention 1600 Clifton Rd. Atlanta, GA 30333, USA

800-CDC-INFO (800-232-4636) TTY: (888) 232-6348 - Contact CDC-INFO 